\title{
O debate teórico a respeito da reforma agrária
}

\author{
El debate teórico sobre la reforma agraria
}

\section{Theoretical debate about agrarian reform}

\author{
Estevan Coca \\ estevanleopoldo@yahoo.com.br \\ Universidade Estadual Paulista
}

\begin{abstract}
Resumo: Neste trabalho analisamos as posturas de alguns intelectuais sobre o significado da reforma agrária nas últimas décadas. Estas análises vão desde aquelas que a consideram geradoras de mudanças estruturais na sociedade até as que a defendem como uma medida que fomentaria o capitalismo. Alguns consideram ter neutralidade em suas posições, outros admitem que política e produção teórica não se separam. É neste emaranhado de abordagens e concepções que o conceito tem sido tratado por teóricos, inseridos na academia ou não. Conhecer este debate é de fundamental importância para entendermos os posicionamentos de governos e instituições, já que muitos desses intelectuais acabam influenciando-os de alguma forma. A produção teórica é um elemento de grande relevância para a discussão sobre a desconcentração de terra e poder em um determinado país.
\end{abstract}

Palavras-chave: Reforma agrária. Campesinato. Assentamentos rurais. Território. Estado.

Resumen: En este trabajo se analizan las actitudes de algunos intelectuales sobre el significado de reforma agraria en las últimas décadas. Los análisis van desde aquellas posiciones que la creen generadoras de cambios estructurales en la sociedad hasta otras que la sostienen como una medida que promovería el desarrollo del capitalismo. Algunos consideran que el concepto posée la neutralidad en sus posiciones, otros admiten que el trabajo político y teórico son inseparables. Los enfoques y concepciones con los cuales se ha tratado la cuestión son apropriados no solamente por los teóricos de la academia. Conocer este debate es crucial para entender las posiciones de los gobiernos y de las instituciones, ya que muchos de los intelectuales terminan influyendo aquellos. Como tal, la producción teórica es un elemento de gran relevancia para la discusión de la desconcentracción de la tierra y el poder en un supuesto país.

Palabras clave: Reforma agraria. Campesinato. Asentamientos rurales. Territorio. Estado.

Abstract: This paper analyzes the attitudes of some intellectuals regarding the meaning of agrarian reform in recent decades. These analyses include the opinions of those who believe that agrarian reform would cause structural changes in society, and those who consider that if it was implemented it would promote capitalism. Some adopt a neutral position but others admit that political and theoretical aspects are inseparable. It is within this tangle of approaches and conceptions that the concept has been treated by theorists, whether they are academic or not. Understanding this debate is crucial to understanding the positions of governments and institutions, since they are ultimately 
influenced by many of these intellectuals. As such, theoretical production is an element of great relevance to discussions about land and power in a given country.

Keywords: Agrarian reform. Peasantry. Rural settlements. Territory. State.

\section{INTRODUÇÃO}

Este artigo é resultado de reflexões realizadas no Núcleo de Estudos, Pesquisas e Projetos de Reforma Agrária (NERA), vinculado ao Departamento de Geografia da Faculdade de Ciências e Tecnologia da Unesp. Por meio dessas reflexões temos buscado compreender o significado da reforma agrária na atual conjuntura da questão agrária brasileira, considerando a diversidade do campesinato e suas diferentes demandas.

Neste trabalho, analisamos as posturas de alguns intelectuais sobre o significado da reforma agrária nas últimas décadas. Estas análises vão desde aquelas que consideram que ela geraria mudanças estruturais na sociedade até as que a defendem como uma medida que fomentaria o capitalismo. Alguns consideram ter neutralidade em suas posições, outros admitem que política e produção teórica não se separam. É neste emaranhado de abordagens e concepções que o conceito tem sido tratado por teóricos, inseridos na academia ou não. Conhecer este debate é de fundamental importância para entendermos os posicionamentos de governos e instituições, já que muitos desses intelectuais acabam influenciando-os. Assim, a produção teórica é gerada por e gera posicionamentos frente ao problema da desconcentração de terra e poder em determinado país.

\section{ANTONIO GARCÍA NOSSA E POSSIBILIDADE DE A REFORMA AGRÁRIA SER REVOLUCIONÁRIA OU NÃO}

Uma importante contribuição para o entendimento do conceito de reforma agrária é oferecida pelo sociólogo colombiano Antonio García Nossa. Ele apresenta uma tipologia das experiências de reforma agrária realizadas na América Latina, demonstrando como ela varia de acordo com a correlação de forças que determina a configuração política de cada país. São elencados três tipos de reforma agrária: estrutural, convencional e marginal.

A reforma agrária estrutural é a mais drástica entre os tipos elencados pelo autor. Ela é parte de um processo de transformações revolucionárias, pelas quais se aspira a uma nova ordem econômica e social. Este processo gera a mudança do status quo, ocasionando o surgimento de novas forças sociais. Ela está relacionada ao processo pelo qual é gerada uma nova sociedade. São substituídas ou alteradas as relações tradicionais de poder e modificadas as regras institucionais (GARCÍA, 1973). A reforma agrária estrutural pode ocorrer no capitalismo, como no caso do México, ou no socialismo, como se deu em Cuba.

Este tipo pode ser entendido como uma revolução agrária. De acordo com Luxemburgo (1986), ao delinear os objetivos da social-democracia alemã, a revolução é 
um processo mais amplo do que a simples reforma, contudo as reformas podem contribuir para a revolução:

Pode, portanto, a social-democracia opor-se às reformas sociais? Ou pode impor à revolução social, a subversão da ordem estabelecida, que é o seu objetivo social último? Evidentemente que não. Para a social-democracia lutar dia a dia, no interior do próprio sistema existente, pelas reformas, pela melhoria da situação dos trabalhadores, pelas instituições democráticas, é o único processo de iniciar a luta de classe proletária e de se orientar para o seu objetivo final, quer dizer: trabalhar para conquistar o poder político e abolir o sistema salarial. Entre a reforma social e a revolução, a social-democracia vê um elo indissolúvel: a luta pela reforma social é o meio, a revolução o fim. (LUXEMBURGO, 1986, p. 23).

Portanto, a reforma é uma luta dentro do próprio sistema e a revolução é um novo sistema. A reforma pode ser entendida como parte do processo revolucionário, porém, ela não é o objetivo final.

A reforma agrária do tipo convencional refere-se a um conjunto de operações negociadas entre antigas e novas forças sociais. Busca-se modificar o monopólio latifundiário sem mudar as regras institucionais da sociedade tradicional. O objetivo é alterar as relações de poder no campo, através de um pacto social estabelecido entre forças sociais antagônicas. Isto ocorre por meio do sistema institucionalizado de partidos, sejam eles conservadores ou revolucionários. Este tipo de reforma agrária ocorre no capitalismo, não visa alterá-lo.

A reforma agrária do tipo marginal não gera a ruptura com o monopólio senhorial da terra, ocasionando reparações superficiais sobre essas estruturas. É uma medida tomada para amenizar a pressão camponesa. Ela se apoia no sistema tradicional de partidos e nas regras institucionais da sociedade tradicional. São geradas medidas paliativas ou compensatórias, com o intuito de conter as pressões populares por uma efetiva reforma agrária. Reformas deste tipo expressam a intenção de não gerar modificações na propriedade fundiária. Não apontam para o rompimento com o capitalismo, ao contrário, criam meios de preservá-lo. Mais adiante, o autor considera este tipo de ação como uma autêntica "contra-reforma agrária" (GARCÍA, 1973).

Assim, a tipologia elaborada por García mostra, sociologicamente, como, dependendo da correlação de forças que existe em determinado país, a reforma agrária terá um impacto social maior ou menor. Contudo, podemos considerar que enquanto a convencional e a marginal podem ser consideradas como reformas, a estrutural possui um impacto ainda maior, sendo considerada como revolução. Reformas ocorrem como meio de melhorar uma estrutura que não é substituída, já as revoluções alteram as estruturas existentes.

É importante frisar que esta tipologia tem como base as experiências realizadas na América Latina até a década de 1960, quando setores da sociedade tinham a intenção de, com a reforma agrária, atingir o latifúndio e as relações de poder estabelecidas e perpetuadas através dele. A sociedade não tinha graus de urbanização tão elevados como a de hoje e a agricultura mecanizada ainda era incipiente, ou seja, a questão agrária possuía diferentes especificações. 


\section{ALBERTO PASSOS GUIMARÃES E CAIO PRADO JÚNIOR: DEBATES SOBRE A REFORMA AGRÁRIA NO PARTIDO COMUNISTA BRASILEIRO}

No Brasil, o debate sobre a reforma agrária seria fomentado com o fim do período conhecido como Estado Novo (1937-1945). Dois fatos que influenciaram a eminência destas discussões foram as constantes secas no Nordeste e o crescente êxodo rural. Dentre os vários setores da sociedade que passam a debater o tema, destaca-se o Partido Comunista Brasileiro (PCB), que entre as décadas de 1950 e 1960 reunia em seus quadros intelectuais militantes que se dedicaram à análise dos problemas agrários do país. A produção destes intelectuais militantes traz discordâncias teóricas e políticas sobre o papel da reforma agrária para o desenvolvimento brasileiro. Um dos principais temas de divergência estava na ocorrência ou não do feudalismo no Brasil colonial. Enquanto alguns defendiam a tese de que no período colonial brasileiro vigoraram relações de produção feudais, outros defendiam que, desde quando ocorreu a dominação portuguesa sob o território nacional, já eram efetivadas relações capitalistas.

No grupo dos que defendiam a primeira tese está Alberto Passo Guimarães. Ele apresentou críticas aos intelectuais que defendiam a tese que o Brasil, desde a dominação portuguesa, esteve sob a égide de uma formação social capitalista. Se ssim entendido, seria supérflua qualquer necessidade de mudança na estrutura agrária do país. As críticas ainda prosseguem quando ele taxa esse tipo de interpretação de evolucionista, não reformista e não revolucionária, já que defende o desenvolvimento gradual sem a realização de reformas. Pequenas medidas pontuais sobre a estrutura agrária estão em voga, como a adubação e a mecanização, que seriam suficientes para acelerar o processo produtivo no campo e excluir a necessidade da realização de reformas.

A reforma agrária seria uma medida que contribuiria para a extinção das relações feudais no campo brasileiro, através de uma ação revolucionária, como consta no trecho a seguir:

A negação ou mesmo a subestimação da substância feudal do latifundismo brasileiro retira da reforma agrária sua vinculação histórica, seu conteúdo dinâmico e revolucionário. Esse conteúdo dinâmico e revolucionário, na presente etapa da vida brasileira, expressa-se pelo objetivo principal do movimento pela reforma agrária, que é o de extirpar e destruir, em nossa agricultura, as relações de produção do tipo feudal e não as relações de produção do tipo capitalista. (GUIMARÃES, 1989, p. 34).

Em consonância com o que pensava o PCB, esta proposta sobre a reforma agrária indicava para o rompimento com o monopólio da terra e das relações de produção pré-capitalistas, que contribuíam para que existissem os privilégios da elite agrária. As propostas que negavam a existência do feudalismo na formação econômica brasileira eram taxadas de conservadoras. A reforma agrária não era encarada como uma política de cunho socialista, mas, sim, como parte da expansão do capitalismo no país. Em um primeiro momento seriam consolidadas as instituições burguesas e a economia capitalista para que estes gerassem as contradições necessárias para a eminência da revolução socialista. 
Também membro do PCB, porém, negando a tese dos resquícios feudais no Brasil, Caio Prado Júnior foi outro intelectual que elaborou uma análise sobre a conjuntura agrária brasileira. Através de textos publicados na Revista Brasiliense, o autor apresenta sua interpretação sobre a questão agrária brasileira e aponta algumas medidas que poderiam ser tomadas para contê-la. No texto "Contribuição para a análise da Questão Agrária no Brasil", publicado em 1960, ele mostra como os principais responsáveis pelas desigualdades econômicas no campo eram a exploração agromercantil e a concentração da propriedade fundiária, e não apenas o latifúndio improdutivo, como muitos entendiam naquele momento. Somente com a reforma agrária ocorreriam as transformações que elevariam o nível de vida da população miserável do campo:

Não é assim de esperar que a evolução da economia agrária se oriente para a transformação de seu tipo de estrutura, sem o concurso de fatores estranhos e que imprimam a essa evolução um sentido predeterminado. Numa palavra, sem a reforma agrária. Para que a utilização da terra deixe de ser o grande negócio de uma reduzida minoria, e se faça em benefício da população trabalhadora rural que tira dessa terra o seu sustento, é preciso que se favoreça e fomente por medidas adequadas o acesso da mesma população trabalhadora à propriedade fundiária. Esse seria o ponto fundamental da reforma agrária, pois com a sua realização se atingiria o essencial que a reforma agrária tem em vista: a elevação do nível da vida da população rural. (PRADO JÚNIOR, 2000. p. 82-83).

O autor aponta a desconcentração fundiária como uma medida de combate às desigualdades econômicas no campo. Essas desigualdades teriam origem na relação entre os poucos proprietários detentores do monopólio da terra e das oportunidades de emprego e a massa de trabalhadores que viviam em condição de miséria. A reforma agrária é apresentada como a única medida capaz de eliminar estas discrepâncias, sem ela as transformações na economia agrária não seriam capazes de alterar a estrutura fundiária.

No ano de 1962, através de um texto intitulado "Nova contribuição para a análise da Questão Agrária no Brasil", Caio Prado Júnior amplia sua concepção de reforma agrária, incorporando, além da necessidade de desconcentração fundiária, a criação de uma legislação trabalhista para o homem do campo. Ele deixa claro que a reforma agrária não pode ser confundida apenas como o aperfeiçoamento e a elevação do nível tecnológico da exploração do campo, pois ela deve ter como objetivo principal a melhoria da qualidade de vida da população rural. De tal maneira:

São assim, em suma, duas as frentes de ataque da reforma agrária: a extensão da proteção legal ao trabalhador rural, e o favorecimento de seu acesso à propriedade e utilização da terra. É muito importante a colocação do nosso problema agrário nessa dupla perspectiva, acentuando o caráter alternativo em que se relacione e combinam as duas soluções propostas. Isso porque seria inteiramente falso imaginar (como pensa um certo sectarismo de esquerda) o desaparecimento desde logo da relação de emprego no trabalho rural, e a transformação instantânea, ou mesmo a curto prazo da massa rural brasileira. (PRADO JÚNIOR, 2000. p. 90). 
A definição de reforma agrária apresentada pelo autor parte de duas ações: a desconcentração fundiária e a criação de uma legislação trabalhista para a população rural. No que se refere à necessidade de mudanças na estrutura fundiária, o pensamento do autor convergia com o que era defendido pelo PCB, todavia, este partido não concordava quanto à urgência da criação de uma legislação voltada para os trabalhadores do campo, como já ocorria na cidade. Enquanto Prado Júnior (2000) acreditava que a criação da legislação trabalhista fortaleceria a população camponesa, passo essencial para que futuramente eles pudessem ser incorporados na luta por uma sociedade socialista, o PCB julgava que tais medidas eram de caráter conservador e não apontavam para a mudança do capitalismo.

Assim, o debate entre Alberto Passos Guimarães e Caio Prado Júnior dá a tônica das discrepâncias que os teóricos do PCB demonstravam em relação às políticas agrárias. A discussão sobre a existência ou não do feudalismo no período de formação social do Brasil é a gênese da divergência entre os dois pensadores. Guimarães propõe mudanças mais radicais, com a eliminação dos restos feudais que eram gerados pelo sistema latifundista e o estabelecimento pleno do capitalismo para que surgissem as contradições propícias à revolução socialista. Prado Júnior, ao contrário, considera que o capitalismo já estava em vias de desenvolvimento no Brasil, e que deveriam ser tomadas medidas no campo com o intuito de fortalecer a classe trabalhadora. Essas medidas se resumiam às ações de desconcentração fundiária e criação de uma legislação que amparasse os trabalhadores.

\section{JOSÉ GOMES DA SILVA: A REFORMA AGRÁRIA AMPLA, IMEDIATA E DRÁSTICA}

A atuação dos intelectuais militantes no PCB mostra como produção teórica e política são processos indissociáveis. A produção intelectual gera políticas e as opções políticas influenciam a produção intelectual. Personagem importante da luta pela reforma agrária no Brasil, o engenheiro agrônomo José Gomes da Silva demonstra muito bem essa relação dialética. Apesar de nunca ter mantido vínculo com partidos políticos, as suas ideias ainda hoje são uma grande referência na luta pela redemocratização do acesso à terra no Brasil. José Gomes é uma figura lembrada com admiração por movimentos socioterritoriais e instituições que defendem a reforma agrária como uma política de fortalecimento do campesinato enquanto classe social.

Silva (1971) busca esclarecer o que de fato vem a ser a reforma agrária, diferenciando-a das demais políticas destinadas ao campo. Demonstra como ela possuía até aquele momento uma definição imprecisa, fato que colaborava para que ela não fosse aplicada, como desejavam as forças contrarreformistas da sociedade. Na época em que esta obra foi escrita, o regime militar dedicava-se à criação de projetos de colonização, através de ações previstas no Estatuto da Terra. O autor deixa explícito que este tipo de política deve ser dissociado da reforma agrária. Neste sentido, ele propõe uma conceituação diferenciada para a reforma agrária no Brasil, definindo-a da seguinte maneira: 
Reforma Agrária é o processo amplo, imediato e drástico de redistribuição de direitos sobre a propriedade privada da terra agrícola, promovido pelo Governo, com a ativa participação dos próprios camponeses e objetivando sua promoção humana, social, econômica e política. (SILVA, 1971, p. 38)

Nesta definição alguns pontos são de extrema importância para termos clara a ideia do autor. A palavra terra refere-se a tudo o que está ligado ao solo, desde as profundezas até o céu, incluindo os corpos de água, a vegetação e outros recursos naturais. A reforma agrária é entendida como um processo que deve ter local e prazo definidos para sua efetivação. Deve atender parte significativa da população sem-terra, de maneira imediata, não podendo se arrastar pelo tempo. Deve modificar o status quo no campo, causando impactos estruturais. Os beneficiários do processo (camponeses sem-terra) têm de ter ativa participação na definição das políticas, não as deixando a cargo apenas dos técnicos estatais. A reforma deve gerar a promoção humana dos sem-terra, já que todo o processo está centrado no homem. A promoção social ocorreria com o fortalecimento dos camponeses enquanto classe; a econômica se daria com o fortalecimento quantitativo e qualitativo da produção no campo, substituindo o latifúndio por outros sistemas mais modernos; e a política ocorreria com a proposição de um modelo de desenvolvimento alternativo, baseado na produção camponesa.

\section{JOÃO PEDRO STÉDILE: A PROPOSTA DE REFORMA AGRÁRIA DOS MOVIMENTOS SOCIOTERRITORIAIS PROGRESSISTAS}

Política e teoria também se inter-relacionam na interpretação do economista e dirigente nacional do Movimento dos Trabalhadores Rurais Sem-Terra (MST), João Pedro Stédile. Ele também se destaca na busca pela definição do papel da reforma agrária na sociedade brasileira. Em entrevista concedida ao professor Bernardo Mançano Fernandes, ele diz que a reforma agrária pode ocorrer de três maneiras: clássica, política de assentamentos e progressista.

A reforma agrária clássica é realizada sob bases capitalistas, com o intuito de democratizar a propriedade da terra, distribuindo-a aos camponeses e transformando-os em pequenos produtores autônomos. Com isso, aumentam a oferta de mercadorias e o mercado consumidor, com o crescimento da renda dos camponeses. Reformas deste tipo foram efetivadas por alguns países sob a influência da burguesia industrial no período que compreende o final do século XIX, e o final da Segunda Guerra Mundial. Tais reformas apresentam três características fundamentais:

a) foram feitas de forma massiva, ou seja, atingiram todas as grandes propriedades do país; b) em alguns lugares impuseram inclusive tamanho máximo da propriedade (caso da França, dos Estados Unidos, na lei de colonização, e no Japão); c) foram rápidas, em um ou dois anos se realizaram (STÉDILE; FERNANDES, 1999, p. 158).

Portanto, este tipo de reforma agrária atingiria a estrutura da propriedade da terra. Seria fomentado o capitalismo nos países que a efetivassem, contribuindo, de 
maneira especial, para que fossem criadas as condições que propiciariam o futuro desenvolvimento industrial. Em Stédile e Fernandes (1999), frisa-se ainda que no Brasil as elites nunca tiveram a intenção de realizar este tipo de reforma agrária, mesmo ela tendo bases capitalistas. Isso porque no país, desde a colonização, tem-se desenvolvido um capitalismo dependente, que tem por base a agricultura de exportação. Neste caso, não há necessidade de se dividir a terra para gerar o crescimento econômico.

O segundo tipo ocorre quando a política de implantação de assentamentos rurais é confundida com a reforma agrária. Trata-se de uma política de assistência social apenas para se livrar dos sem-terra, e não para resolver o problema da propriedade da terra. Estas ações ocorrem como forma de conter os conflitos por terra, sendo que, apesar da implantação dos assentamentos, não existe um plano geral que vise à desconcentração fundiária. Ou seja, fazer assentamento não significa fazer reforma agrária (STÉDILE; FERNANDES, 1999).

O terceiro tipo é o preconizado pelas forças sociais progressistas, dentre as quais estão incluídos movimentos socioterritoriais como o MST e a Confederação Nacional dos Trabalhadores na Agricultura (CONTAG). Busca-se resolver o problema da concentração da propriedade da terra através de um programa de desapropriações, de forma rápida, regionalizada, distribuindo as terras às famílias que não as possuem. A desconcentração da propriedade da terra seria uma das medidas de combate aos dois principais problemas que existem no meio rural brasileiro: a pobreza e as desigualdades sociais. Também objetiva democratizar o capital, criando condições para que o camponês assentado tenha boas condições de produção e comercialização. Além disso, a reforma agrária não deve ser dissociada da redemocratização da educação, já que na sociedade moderna, "conhecimento, cultura, informação é poder" (STÉDILE; FERNANDES, 1999, p. 162), e para que os camponeses possam se colocar de maneira autônoma frente aos desafios impostos pela modernidade é necessário acesso à educação. Stédile (1999 p. 162) resume este tipo de reforma agrária da seguinte maneira:

[...] dizemos que nossa reforma agrária é na verdade uma luta contra três cercas. A cerca do latifúndio, que é a mais fácil de derrubar, é só ocupar. A cerca do capital, já mais difícil, ter acesso, construir nossas agroindústrias; e a cerca da ignorância. (STÉDILE, FERNANDES, 1999, p. 162).

Assim, Stédile demonstra entender que o terceiro tipo seria o ideal para o Brasil, dado o estágio de desenvolvimento do capitalismo no país. O autor situa as características da reforma agrária por ele defendida, mas frisa, de maneira especial, os entraves encontrados para sua efetivação, sendo eles o latifúndio, o capital e a ignorância.

\section{BERNARDO MANÇANO FERNANDES: A REFORMA AGRÁRIA COMO POLÍTICA DE DESENVOLVIMENTO TERRITORIAL}

Outro intelectual vinculado ao MST que propõe uma definição da reforma agrária e aponta os obstáculos para sua efetivação é o geógrafo Bernardo Mançano Fernandes. 
Ele destaca a disputa por território entre os modelos de desenvolvimento do agronegócio e da reforma agrária. O agronegócio tem sido beneficiado por vultosos incentivos financeiros concedidos pelo Estado, o qual o entende como uma totalidade, da qual a agricultura camponesa ou de base familiar faz parte. Sendo assim, a luta pela terra e a reforma agrária são importantes instrumentos de resistência camponesa, como aduz o autor:

[...] a luta pela terra e a reforma agrária formam o principal fator de territorialização do campesinato no território nacional. O desenvolvimento territorial e reforma agrária são processos indissociáveis. Portanto, a obtenção de terras e o desenvolvimento dos assentamentos são processos inseparáveis. O capital forma os seus territórios e se territorializa, ou seja, se expande multiplicando o controle de enormes áreas em todas as regiões. Na atualidade, no campo brasileiro, o capital tem o nome de agronegócio, que procura se apropriar das terras e subalternizar o campesinato através da terceirização da produção (que muitos chamam de integração) ou expropriá-lo através da verticalização da produção, controlando todos os sistemas que o compõem. (FERNANDES, 2007. p. 86).

Portanto, a reforma agrária é tida como uma política de desenvolvimento que garante a territorialização do campesinato. A territorialização vai além da conquista de terras; ela é a expansão das relações de poder no espaço geográfico, é o confronto entre a propriedade capitalista e a propriedade camponesa (FERNANDES, 2003). A obtenção de terras não deve ser o objetivo final da reforma agrária, pois deve-se pensar os assentamentos como uma proposta de desenvolvimento, pela qual seria gerada a agricultura de base camponesa.

\section{GUILHERME DELGADO: A REFORMA AGRÁRIA E A DISPUTA POR TERRITÓRIOS COM O AGRONEGÓCIO}

A disputa territorial entre o agronegócio e a reforma agrária também tem sido debatida pelo economista Guilherme Delgado. Em entrevista ao Jornal Brasil de Fato, ele defende que a reforma agrária ainda não foi alvo de um programa oficial por parte do Estado. A facilidade com que o agronegócio tem se apoderado das áreas agrícolas do território nacional tem acarretado grandes prejuízos à nação, já que ele não cumpre com suas funções sociais, ambientais e de posse da terra, além de não respeitar as relações de trabalho. Nessas condições, a reforma agrária, aplicada de forma includente, seria a solução para estes empecilhos. Neste sentido, assim argumenta Delgado (2008):

Muitas vezes, se coloca a reforma agrária como um programa oficial, mas não encontramos isso. Afirma-se que o Brasil está fora da curva e que, hoje, não se faz mais reforma agrária. A questão é discutir como inserimos os pequenos estabelecimentos. Mesmo no modelo capitalista, temos variantes da maior diferença. A experiência europeia do pós-guerra permite que, sem uma reforma agrária clássica, as pequenas propriedades coexistam sem serem engolidas pelo 
agronegócio internacional. Esse padrão de desenvolvimento - que chamaríamos de uma política agrária condizente com a realidade - abriria espaço para setores do campo participarem do desenvolvimento de forma mais includente. Mas, para isso, há a necessidade de uma política econômica distinta. Nosso modelo não é parecido com o europeu nem o dos Estados Unidos, apesar de muitos dizerem que é a nossa inspiração. O nosso agronegócio é mais desigual do que o deles. Após a abolição e a guerra civil, houve uma mudança na estrutura de posse da terra e uma ocupação do meio-oeste dos EUA. Já nós chegamos ao século 20 sem fazer nenhuma dessas mudanças. E descartamos fazê-las porque dizemos que passou o tempo. Não se passou do tempo de uma política de igualdade e distribuição. Mudaram, sim, os instrumentos, as estruturas de intervenção. Precisamos de uma política comum que tenha capacidade de impedir o avanço do agronegócio, com a liberdade que tem hoje. Ele não tem obrigações com sua função social, obrigações de posse da terra, de meio ambiente e de respeito às relações de trabalho. $\mathrm{O}$ caso brasileiro é ímpar de desigualdade crescente. Um formato de reforma agrária includente, de desenvolvimento e igualdade não está fora da agenda ao menos que se pense que não há desigualdade no país. O pessoal acha que desenvolvimento é modernização conservadora. É a moda Geisel, desenvolver o modelo do regime militar. Agora, o Brasil precisa de uma política clara de contenção da liberdade de ação do agronegócio. Sem isso, a reforma agrária é engodo, tão residual e incapaz de se manter que será engolida. (DELGADO, 2008, p.20).

Tanto Guilherme Delgado quanto Bernardo Mançano Fernandes destacam o agronegócio como o grande rival da reforma agrária na disputa pelas terras agricultáveis do Brasil. Isso mostra a evolução do debate, já que antes o latifúndio era tido como o principal obstáculo para que a reforma agrária fosse efetivada. Além do mais, discute-se agora não apenas a necessidade de desapropriar áreas, entregando-as a camponeses sem-terra, mas, sim, a mudança dos paradigmas de desenvolvimento adotados no campo. A reforma agrária não é entendida apenas como uma medida conjuntural, de alívio da pobreza, mas como um modelo alternativo de desenvolvimento para o campo. Ela garante território para que o campesinato desenvolva seu modo de vida e produção, valorizando o trabalho de base familiar, a produção diversificada e em pequena escala e gerando uma paisagem heterogênea no campo. $\mathrm{O}$ agronegócio, ao contrário, gera relações como o trabalho assalariado, a produção em larga escala e a homogeneidade da paisagem. Portanto, reforma agrária e agronegócio não são entendidos como modelos de desenvolvimento complementares, mas como opostos, dadas as diferentes relações sociais que produzem.

\section{ARIOVALDO UMBELINO DE OLIVEIRA: A REFORMA AGRÁRIA PARA ALÉM DO ALCANCE SOCIAL}

Outro autor que aborda a reforma agrária enquanto política de desenvolvimento é o geógrafo Ariovaldo Umbelino de Oliveira. Ao analisar a demanda por reforma agrária 
no Brasil, ele entende que esta não possui apenas alcance social, mas também político e econômico, como se observa a seguir:

No Brasil é quase consenso que qualquer alternativa de remoção da exclusão social neste país passa pela Reforma Agrária. Ela tem, portanto, um objetivo social, ou seja, é o caminho para retirar da marginalidade social no mínimo, uma parte dos pobres. Mas a Reforma Agrária é também econômica, porque ela certamente levará a um aumento ainda maior da oferta de produtos agrícolas destas pequenas unidades ao mercado. Mas a Reforma Agrária tem que ser também política. Tem que ser instrumento através do qual, esta parcela da população conquista a cidadania. (OLIVEIRA, 2007, p. 146).

O autor aborda a reforma agrária mostrando os impactos que ela pode causar nas diversas dimensões sociais. Ele faz uma interpretação multidimensional do processo, ao contrário da abordagem contida em grande parte das políticas públicas. A reforma agrária possui alcance social, já que possibilita ao campesinato o acesso à terra, que é seu principal instrumento de trabalho, possibilitando melhores condições de vida a pessoas que estavam em situação de miséria. Possui alcance econômico, pois fomenta o mercado interno, com a oferta de produtos e com o aumento da renda por parte dos camponeses. Possui alcance político, pois o campesinato se posiciona enquanto classe social na luta pela manutenção do seu estilo de viver e trabalhar.

Nesta obra, Ariovaldo Oliveira também demonstra o que não é a reforma agrária. O autor apresenta uma crítica à maneira como foram divulgados os dados sobre assentamentos rurais do primeiro mandato de Luís Inácio Lula da Silva como Presidente da República. De acordo com ele, a incoerência está em afirmar que ações como a regularização fundiária, o reordenamento fundiário, o reassentamento de atingidos por barragens e o reconhecimento de assentamentos criados por outros governos são reforma agrária. Isso faz com que a criação de assentamentos novos, especialmente através da desapropriação de terras, seja colocada no mesmo patamar que essas ações, assim se chega à conclusão que neste período houve uma "não reforma agrária".

\section{JOSÉ DE SOUZA MARTINS: A REFORMA AGRÁRIA COMO A RETOMADA DO TERRITÓRIO POR PARTE DO ESTADO}

Já o sociólogo José de Souza Martins defende que não é a quantidade que define a reforma agrária, mas a qualidade. $\mathrm{O}$ autor qualifica que a conquista de territórios de assentamentos é um fator secundário se comparado à conquista de um espaço no mercado por parte da agricultura familiar. Para ele:

A reforma agrária é um tema político que se propõe em termos qualitativos e não em termos quantitativos. Não é o número de desapropriações ou o número em terras desapropriadas ou compradas que definem o perfil da reforma agrária brasileira, sua justeza ou não. O essencial é que haja um setor ponderável da sociedade reivindicando a ampliação do lugar da agricultura familiar no sistema econômico e que em parte 
essa agricultura familiar esteja nas mãos de pessoas que se ressocializaram na luta pela reforma agrária e nela se politizaram. (MARTINS, 2000. p. 103-104).

Assim, ele defende que seria assegurada no interior e no campo a diversificação das oportunidades de trabalho, além da modernização não só econômica como também das mentalidades e das relações sociais. Todavia, nessa análise Martins não leva em consideração a enorme massa de camponeses acampados na beira das rodovias e que clamam por território, na espera pelo assentamento. Evidente que para esses autores quantidade e qualidade formam uma condição de realização da reforma agrária. São, portanto inseparáveis.

Ainda nesta obra é demonstrada a compreensão de que os posicionamentos que entendem a desapropriação como a única política de obtenção de terras capaz de efetivar a reforma agrária é incoerente com a luta dos camponeses brasileiros. Martins justifica essa afirmação demonstrando que, já nas décadas de 1950 e 1960, os posseiros da Amazônia e do Centro-Oeste lutavam pela regularização das terras em que viviam. A regularização fundiária deveria ser entendida como a tentativa do Estado de retomar o controle do território, perdido com a Lei de Terras, de 1850, e controlar o processo de expropriação dos camponeses.

\section{CONSIDERAÇÕES FINAIS}

Apresentamos neste trabalho diferentes abordagens de intelectuais sobre o significado da reforma agrária. O que diferencia essas abordagens são os elementos que cada autor julga pertinente para a interpretação que faz. Isso depende da postura ideológica que cada um deles possui.

\section{REFERÊNCIAS}

DELGADO, G. C. Lula abandonou a reforma agrária, diz pesquisador. Brasil de Fato, 18, abr, 2008. Caderno Nacional.

FERNANDES, B. M. Territórios da questão agrária: campesinato, reforma agrária e agronegócio. Revista Brasileira de Reforma Agrária, São Paulo, 2007. v.4, n.2. p. 77-94, jul/dez. 2007.

. Reforma agrária no governo Lula: a esperança. Presidente Prudente: NERA, 2003. Disponível em: <http://www4.fct.unesp.br/nera/publicacoes/LULA_RA.pdf>. Acesso em: 28 out. 2010.

GARCIA, A. Sociologia de la reforma agraria em América Latina. Buenos Aires: Amorrotu, 1973.

GUIMARÃES, A. P. Quatro séculos de latifúndio. Rio de Janeiro: Paz e Terra, 1989.

LUXEMBURGO, R. Reforma Social ou Revolução? São Paulo: Global, 1986.

MARTINS, J. S. Reforma agrária - o impossível diálogo. São Paulo: Editora da Universidade de São Paulo, 2000.

OLIVEIRA, A. U. Modo capitalista de produção, agricultura e reforma agrária. São Paulo: Labur Edições, 2007.

PRADO JÚNIOR, C. A questão agrária no Brasil. São Paulo: Brasiliense, 2000. 
SILVA, J. G. A reforma agrária no Brasil. Rio de Janeiro: Zahar Editores, 1971.

STÉDILE, J. P.; FERNANDES, B. M. Brava gente: a trajetória do MST e a luta pela terra no Brasil. São Paulo, Fundação Perseu Abramo, 1999.

Recebido em 10-07-2013

Aceito para publicação em 13-02-2014 